\title{
Cobalt(II) Chloride Hexahydrate as an Efficient and Inexpensive Catalyst for the Preparation of Biscoumarin Derivatives
}

\author{
Mohammad Reza Nazarifar \\ Young Researchers and Elites Club, Shiraz Branch, Islamic Azad University, Shiraz, Iran \\ Correspondence should be addressed to Mohammad Reza Nazarifar; mohammadreza.nazarifar@gmail.com
}

Received 23 June 2014; Accepted 26 September 2014; Published 12 October 2014

Academic Editor: Georgia Melagraki

Copyright ( 2014 Mohammad Reza Nazarifar. This is an open access article distributed under the Creative Commons Attribution License, which permits unrestricted use, distribution, and reproduction in any medium, provided the original work is properly cited.

Cobalt(II) chloride hexahydrate $\left(\mathrm{CoCl}_{2} \cdot 6 \mathrm{H}_{2} \mathrm{O}\right)$ has been found to be an efficient catalyst for the one-pot synthesis of biscoumarin derivatives through a combination of aromatic aldehydes and 4-hydroxycoumarin in aqueous media at $70^{\circ} \mathrm{C}$. Several types of aromatic aldehyde, containing electron-withdrawing groups as well as electron-donating groups, were used in the reaction and in all cases the desired products were synthesized successfully. The present approach offers remarkable advantages such as short reaction times, excellent yields, straightforward procedure, easy purification, environment friendliness, and low catalyst loading.

\section{Introduction}

Coumarin derivatives, especially biscoumarins, are important compounds in organic synthesis due to their wide spectrum of pharmacological properties such as antifungal, anti-HIV, anticancer, anticoagulant, antithrombotic, antimicrobial, and antioxidant [1-5]. These compounds are also utilized as urease inhibitors [6].

A number of methods have been reported for the synthesis of these compounds in the presence of various catalysts like molecular iodine [7], sodium dodecyl sulfate (SDS) [8], tetrabutylammonium bromide (TBAB) [9], $\left(\left[\mathrm{MIM}\left(\mathrm{CH}_{2}\right)_{4} \mathrm{SO}_{3} \mathrm{H}\right]\left[\mathrm{HSO}_{4}\right]\right) \quad[10]$, tetrabutylammonium hexatungstate $\left([\mathrm{TBA}]_{2}\left[\mathrm{~W}_{6} \mathrm{O}_{19}\right]\right) \quad[11]$, sulfated titania $\left(\mathrm{TiO}_{2} / \mathrm{SO}_{4}{ }^{2-}\right)$ [12], ruthenium(III) chloride hydrate $\left(\mathrm{RuCl}_{3}\right.$ $\cdot n \mathrm{H}_{2} \mathrm{O}$ ) [13], n-dodecylbenzene sulfonic acid (DBSA) [14], and silica chloride nanoparticles (nano $\mathrm{SiO}_{2} \mathrm{Cl}$ ) [15]. However, these methods suffer from one or more disadvantages such as low yields of products, long reaction times, use of expensive catalyst, toxic solvents, or harsh reaction conditions. Therefore, introducing a clean procedure by the use of green and environmentally friendly catalyst with high catalytic activity, moderate temperature, and short reaction time accompanied with excellent yield for the production of biscoumarin derivatives is needed.
We hoped to develop a more general protocol for the efficient synthesis of biscoumarin derivatives via $\mathrm{CoCl}_{2} \cdot 6 \mathrm{H}_{2} \mathrm{O}$, which have recently attracted much attention as catalyst to organic synthesis due to their low toxicity and easy availability [16-18].

\section{Results and Discussion}

We herein present efficient and eco-friendly procedure for the synthesis of biscoumarin derivatives $(3 \mathrm{a}-\mathrm{m})$ by threecomponent condensation of 4-hydroxycoumarin (1) and aromatic aldehyde (2) catalyzed by $\mathrm{CoCl}_{2} \cdot 6 \mathrm{H}_{2} \mathrm{O}$ in waterethanol solvent system $70^{\circ} \mathrm{C}$ (Scheme 1).

For this study, a reaction between 4-hydroxycoumarin ( $2 \mathrm{mmol})$ and 3-nitrobenzaldehyde $(1 \mathrm{mmol})$ was examined as the model reaction. Initial studies showed that better results could be obtained in the presence of $(10 \mathrm{~mol} \%)$ $\mathrm{CoCl}_{2} \cdot 6 \mathrm{H}_{2} \mathrm{O}$ in aqueous ethanol $\left(1: 1, \mathrm{H}_{2} \mathrm{O}: \mathrm{EtOH}\right)$ at $70^{\circ} \mathrm{C}$.

To optimize the mol\% of catalyst, the above reaction was performed with different mol\% of $\mathrm{CoCl}_{2} \cdot 6 \mathrm{H}_{2} \mathrm{O}$ such as 5,10 , 15,20 , and $25 \mathrm{~mol} \%$. The results are summarised in Table 1 which shows that the reaction catalysed by about $10 \mathrm{~mol} \%$ $\mathrm{CoCl}_{2} \cdot 6 \mathrm{H}_{2} \mathrm{O}$ results in the highest yield (Table 1, entry 2). In the presence of less than this amount, the yield decreased 


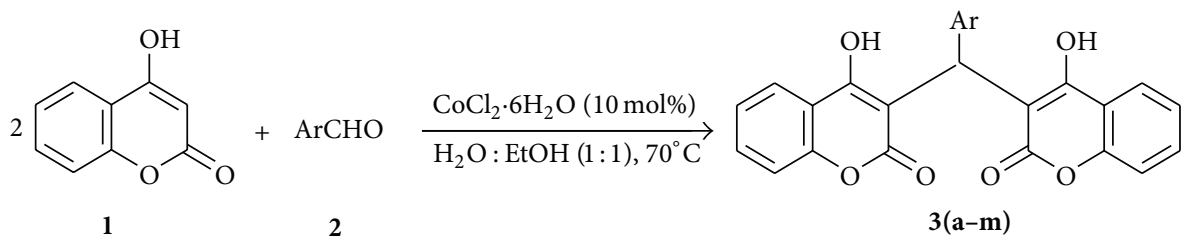

Scheme 1: Synthesis of biscoumarins.

TABLE 1: Optimization of the catalysed model reaction for synthesis of 3,3'-(3-nitrobenzylidene)-bis-(4-hydroxycoumarin).

\begin{tabular}{llccc}
\hline Entry & Catalyst & Amount of catalyst (mol\%) & Time (min) & Yield (\%) \\
\hline 1 & $\mathrm{CoCl}_{2} \cdot 6 \mathrm{H}_{2} \mathrm{O}$ & 5 & 8 & 89 \\
2 & $\mathrm{CoCl}_{2} \cdot 6 \mathrm{H}_{2} \mathrm{O}$ & 10 & 2 & 98 \\
3 & $\mathrm{CoCl}_{2} \cdot 6 \mathrm{H}_{2} \mathrm{O}$ & 15 & 2 & 98 \\
4 & $\mathrm{CoCl}_{2} \cdot 6 \mathrm{H}_{2} \mathrm{O}$ & 20 & 2 & 98 \\
5 & $\mathrm{CoCl}_{2} \cdot 6 \mathrm{H}_{2} \mathrm{O}$ & 25 & 2 & 96 \\
\hline
\end{tabular}

All reactions were carried out in aqueous ethanol at $70^{\circ} \mathrm{C}$.

${ }^{\mathrm{a}}$ Isolated yields.

(Table 1 , entry 1). When the amount of $\mathrm{CoCl}_{2} \cdot 6 \mathrm{H}_{2} \mathrm{O}$ was increased over $10 \mathrm{~mol} \%$, neither the yield nor the reaction time was improved (Table 1, entry 3 ).

To study the effect of temperature on this synthesis, we also performed four experiments in aqueous ethanol at room temperature, 50, and 70 (Celsius degrees) and under reflux condition (Table 2). It was observed that the yield of the product is maximum at $70^{\circ} \mathrm{C}$ (Table 2 , entry 3 ).

During the optimization of the reaction condition, various solvents were also screened to test their efficiency and the results are summarized in Table 3 . The highest reaction activity was achieved in the system using aqueous ethanol $\left(1: 1, \mathrm{H}_{2} \mathrm{O}: \mathrm{EtOH}\right)$ as a solvent in comparison to other solvents under similar reaction conditions (Table 3, entry 5).

With these encouraging results in hand, the generality of this reaction was examined using various aromatic aldehydes containing electron-donating as well as electronwithdrawing groups. In all cases, the reactions gave the corresponding products in good yields and short reaction times without formation of any byproducts (Table 4). Substituents on the aromatic ring had no obvious effect on yield or reaction time under the above optimal conditions.

In order to assess the efficiency of this methodology, the obtained result from the reaction of 3-nitrobenzaldehyde with 4-hydroxycoumarin by this method has been compared with those of the previously reported methods. As demonstrated in Table 5, the use of $\mathrm{CoCl}_{2} \cdot 6 \mathrm{H}_{2} \mathrm{O}$ leads to an improved protocol in terms of compatibility with environment, reaction time, yield of the product, and amount of the catalyst when compared with other catalysts.

\section{Experimental}

3.1. Materials and Methods. All reagents were purchased from Fluka, Merck, and Aldrich with high-grade quality and used without any purification. The reactions were monitored by TLC. Visualisation of the developed chromatogram was performed by UV light (254 nm). All yields refer to isolated products after purification. Products were characterized by comparison with authentic samples and by spectroscopy data (IR, ${ }^{1} \mathrm{H}$ NMR spectra). IR spectra were recorded from $\mathrm{KBr}$ disk on the FT-IR Bruker Tensor 27. ${ }^{1} \mathrm{H}$ NMR spectra were recorded on a Bruker Avance $400 \mathrm{MHz}$ spectrometer using TMS as an internal standard (DMSO- $\mathrm{d}_{6}$ solution). Melting points were measured by using the capillary tube method with IA 9000 series thermal analyser.

3.2. General Procedure for the Synthesis of Biscoumarin Derivatives. A mixture of the 4-hydroxycoumarin $(2 \mathrm{mmol})$, aromatic aldehyde $(1 \mathrm{mmol})$, and $\mathrm{CoCl}_{2} \cdot 6 \mathrm{H}_{2} \mathrm{O}(10 \mathrm{~mol} \%)$ was stirred in $5 \mathrm{~mL}$ aqueous ethanol $\left(1: 1, \mathrm{H}_{2} \mathrm{O}: \mathrm{EtOH}\right) 70^{\circ} \mathrm{C}$ for the appropriate time. Completion of the reaction was indicated by TLC. After the completion, the reaction mixture was filtered off and washed with $n$-hexane $(2 \times 5 \mathrm{~mL})$ to obtain pure products. As the catalyst is completely soluble in distilled water, it was easily separated from the reaction mixture. All of the products are known compounds and were characterized by IR and ${ }^{1} \mathrm{H}$ NMR spectroscopic data and their melting points are compared with reported values.

\subsection{Selected Spectral Data}

3.3.1. 3,3'-(4-Chlorobenzylidene)-bis-(4-hydroxycoumarin) (Table 4, Entry 7): IR(KBr). $3420(\mathrm{OH}), 2923$ (C-H stretching), 1668 ( $-\mathrm{C}=\mathrm{O}$ stretching of $-\mathrm{COOR}$ group), 1606 ( $-\mathrm{C}=\mathrm{C}$ stretching), 1563, 1490 ( $\mathrm{C}=\mathrm{C}$ - stretching of aromatic ring), 765 (C-H out of plane bending) $\mathrm{cm}^{-1} ;{ }^{1} \mathrm{H}$ NMR $(400 \mathrm{MHz}$, DMSO- $\left.\mathrm{d}_{6}\right): \delta 6.63(\mathrm{~s}, 1 \mathrm{H}, \mathrm{CH}), 7.16-7.90(\mathrm{~m}, 12 \mathrm{H}, \mathrm{ArH})$, 7.90-9 (m, 2H, OH).

3.3.2. 3,3'-(3-Nitrobenzylidene)-bis-(4-hydroxycoumarin) (Table 4, Entry 9): IR(KBr). $3424(\mathrm{OH}), 2925$ (C-H stretching), 1655 ( $-\mathrm{C}=\mathrm{O}$ stretching of $-\mathrm{COOR}$ group), $1616(-\mathrm{C}=\mathrm{C}$ stretching), 1564, 1494 ( $\mathrm{C}=\mathrm{C}-$ stretching of aromatic ring), 
TABLE 2: Optimisation of temperature for synthesis of 3,3' -(3-nitrobenzylidene)-bis-(4-hydroxycoumarin) using $\mathrm{CoCl}_{2} \cdot 6 \mathrm{H}_{2} \mathrm{O}(10 \mathrm{~mol} \%)$ as catalyst in aqueous ethanol.

\begin{tabular}{lcccc}
\hline Entry & Catalyst & Temperature ${ }^{\circ} \mathrm{C}$ & Time $($ min $)$ & Yields $(\%)$ \\
\hline 1 & $\mathrm{CoCl}_{2} \cdot 6 \mathrm{H}_{2} \mathrm{O}$ & Room temperature & 4 & 85 \\
2 & $\mathrm{CoCl}_{2} \cdot 6 \mathrm{H}_{2} \mathrm{O}$ & Reflux & 2 & 98 \\
3 & $\mathrm{CoCl}_{2} \cdot 6 \mathrm{H}_{2} \mathrm{O}$ & 70 & 2 & 98 \\
4 & $\mathrm{CoCl}_{2} \cdot 6 \mathrm{H}_{2} \mathrm{O}$ & 50 & 4 & 95 \\
\hline
\end{tabular}

Isolated yield of the pure compound.

TABLE 3: Effect of solvents in reaction of 3-nitrobenzaldehyde and 4-hydroxycoumarin catalyzed by $\mathrm{CoCl}_{2} \cdot 6 \mathrm{H}_{2} \mathrm{O}$.

\begin{tabular}{llccc}
\hline Entry & Catalyst & Solvent & Time (min) & Yields (\%) \\
\hline 1 & $\mathrm{CoCl}_{2} \cdot 6 \mathrm{H}_{2} \mathrm{O}$ & $\mathrm{EtOH}$ & 4 & 9 \\
2 & $\mathrm{CoCl}_{2} \cdot 6 \mathrm{H}_{2} \mathrm{O}$ & $\mathrm{H}_{2} \mathrm{O}$ & 4 & 97 \\
3 & $\mathrm{CoCl}_{2} \cdot 6 \mathrm{H}_{2} \mathrm{O}$ & $\mathrm{H}_{2} \mathrm{O}: \mathrm{EtOH}(1: 2)$ & 3 & 96 \\
4 & $\mathrm{CoCl}_{2} \cdot 6 \mathrm{H}_{2} \mathrm{O}$ & $\mathrm{H}_{2} \mathrm{O}: \mathrm{EtOH}(2: 1)$ & 2 & 98 \\
5 & $\mathrm{CoCl}_{2} \cdot 6 \mathrm{H}_{2} \mathrm{O}$ & $\mathrm{H}_{2} \mathrm{O}:$ EtOH $(1: 1)$ & $2 \mathrm{~h}$ & 98 \\
6 & $\mathrm{CoCl}_{2} \cdot 6 \mathrm{H}_{2} \mathrm{O}$ & Solvent free & Trace \\
\hline
\end{tabular}

All reactions were catalyzed by $\mathrm{CoCl}_{2} \cdot 6 \mathrm{H}_{2} \mathrm{O}$ at $70^{\circ} \mathrm{C}$.

${ }^{a}$ Isolated yields.

TABLE 4: $\mathrm{CoCl}_{2} \cdot 6 \mathrm{H}_{2} \mathrm{O}$ catalyzed synthesis of biscoumarin derivatives ${ }^{\mathrm{a}}$.

\begin{tabular}{|c|c|c|c|c|c|c|}
\hline \multirow{2}{*}{ Entry } & \multirow{2}{*}{$\mathrm{Ar}$} & \multirow{2}{*}{ Product } & \multirow{2}{*}{ Time (min) } & \multirow{2}{*}{ Yield $^{\mathrm{b}}(\%)$} & \multicolumn{2}{|c|}{$m p\left({ }^{\circ} \mathrm{C}\right)$} \\
\hline & & & & & Reported [ref] & This work \\
\hline 1 & $\mathrm{C}_{6} \mathrm{H}_{5}$ & $3 a$ & 2 & 92 & $229-231[10]$ & $230-232$ \\
\hline 2 & $4-\mathrm{FC}_{6} \mathrm{H}_{4}$ & $3 b$ & 2 & 97 & $212-214$ [15] & $211-212$ \\
\hline 3 & $4-\mathrm{BrC}_{6} \mathrm{H}_{4}$ & $3 c$ & 5 & 96 & $266-268$ [15] & $264-266$ \\
\hline 4 & $4-\mathrm{CNC}_{6} \mathrm{H}_{4}$ & $3 d$ & 5 & 96 & $240-242[13]$ & $240-242$ \\
\hline 5 & $2-\mathrm{ClC}_{6} \mathrm{H}_{4}$ & $3 e$ & 3 & 93 & $201-203[10]$ & $200-202$ \\
\hline 6 & $3-\mathrm{ClC}_{6} \mathrm{H}_{4}$ & $3 f$ & 3 & 94 & $221-223[10]$ & $221-223$ \\
\hline 7 & $4-\mathrm{ClC}_{6} \mathrm{H}_{4}$ & $3 g$ & 1 & 97 & $261-263[10]$ & $256-258$ \\
\hline 8 & $2-\mathrm{O}_{2} \mathrm{NC}_{6} \mathrm{H}_{4}$ & $3 \mathrm{~h}$ & 3 & 94 & $198-200[10]$ & 195-197 \\
\hline 9 & $3-\mathrm{O}_{2} \mathrm{NC}_{6} \mathrm{H}_{4}$ & $3 \mathrm{i}$ & 1 & 98 & 235 [19] & $234-236$ \\
\hline 10 & $4-\mathrm{O}_{2} \mathrm{NC}_{6} \mathrm{H}_{4}$ & $3 j$ & 1 & 98 & $232-234[20]$ & $238-239$ \\
\hline 11 & $4-\mathrm{CH}_{3} \mathrm{C}_{6} \mathrm{H}_{4}$ & $3 \mathrm{k}$ & 5 & 92 & $271-273$ [11] & $266-268$ \\
\hline 12 & $4-\mathrm{CH}_{3} \mathrm{OC}_{6} \mathrm{H}_{4}$ & 31 & 4 & 94 & $251-253[11]$ & $246-248$ \\
\hline 13 & $3-\mathrm{CH}_{3} \mathrm{OC}_{6} \mathrm{H}_{4}$ & $3 \mathrm{~m}$ & 5 & 92 & 238 [21] & $238-240$ \\
\hline 14 & $\mathrm{CH}_{3} \mathrm{CHO}$ & - & 120 & - & & \\
\hline
\end{tabular}

TABLE 5: Comparison of the efficiency of $\mathrm{CoCl}_{2} \cdot 6 \mathrm{H}_{2} \mathrm{O}$ with other reported catalysts in the synthesis of 3,3'-(3-nitrobenzylidene)-bis-(4hydroxycoumarin).

\begin{tabular}{|c|c|c|c|c|}
\hline Entry & Catalyst & Conditions & Time & Yield (\%) [ref] \\
\hline 1 & {$\left[\mathrm{P}_{4} \mathrm{VPy}-\mathrm{BuSO}_{3} \mathrm{H}\right] \mathrm{Cl}-\mathrm{X}\left(\mathrm{AlCl}_{3}\right), 0.07 \mathrm{mmol}$} & Toluene, $90^{\circ} \mathrm{C}$ & $0.5(\mathrm{~h})$ & $96[22]$ \\
\hline 2 & SBPPSP, $0.06 \mathrm{~g}$ & $\mathrm{EtOH} / \mathrm{H}_{2} \mathrm{O}$, reflux & $15(\min )$ & $94[20]$ \\
\hline 3 & SDS, $20 \mathrm{~mol} \%$ & $\mathrm{H}_{2} \mathrm{O}, 60^{\circ} \mathrm{C}$ & $2.15(\mathrm{~h})$ & $95[8]$ \\
\hline 4 & Nano- $\mathrm{SiO}_{2} \mathrm{Cl}, 75 \mathrm{mg}$ & $\mathrm{CH}_{2} \mathrm{Cl}_{2}, 40^{\circ} \mathrm{C}$ & $3.5(h)$ & 90 [15] \\
\hline 5 & {$[\mathrm{TBA}]_{2}\left[\mathrm{~W}_{6} \mathrm{O}_{19}\right], 0.08 \mathrm{mmol}$} & EtOH, reflux & $7(\min )$ & $85[11]$ \\
\hline 6 & $\mathrm{NaHSO}_{4} \cdot \mathrm{SiO}_{2}$ or Indion $190 \mathrm{resin}, 150 \mathrm{mg}$ & Toluene, $100^{\circ} \mathrm{C}$ & $30(\min )$ & $90[19]$ \\
\hline 7 & $\mathrm{CoCl}_{2} \cdot 6 \mathrm{H}_{2} \mathrm{O}, 10 \mathrm{~mol} \%$ & $\mathrm{EtOH} / \mathrm{H}_{2} \mathrm{O}, 70^{\circ} \mathrm{C}$ & $2(\min )$ & 98 [present work] \\
\hline
\end{tabular}


$762\left(\mathrm{C}-\mathrm{H}\right.$ out of plane bending) $\mathrm{cm}^{-1} ;{ }^{1} \mathrm{H}$ NMR $(400 \mathrm{MHz}$, DMSO $\left.-\mathrm{d}_{6}\right): \delta 6.39(\mathrm{~s}, 1 \mathrm{H}, \mathrm{CH}), 7.28-8.04(\mathrm{~m}, 12 \mathrm{H}, \mathrm{ArH})$, 8.04-9.52 (m, 2H, OH).

\subsubsection{3,3'-(4-Methoxybenzylidene)-bis-(4-hydroxycoumarin)} (Table 4, Entry 12). IR(KBr): $3443(\mathrm{OH}), 2926$ (C-H stretching), 1668 ( $-\mathrm{C}=\mathrm{O}$ stretching of $-\mathrm{COOR}$ group), $1606(-\mathrm{C}=\mathrm{C}$ stretching), 1563, 1510 ( $\mathrm{C}=\mathrm{C}$ - stretching of aromatic ring), 767 (C-H out of plane bending) $\mathrm{cm}^{-1} ;{ }^{1} \mathrm{H} \mathrm{NMR}(400 \mathrm{MHz}$, DMSO- $\left.\mathrm{d}_{6}\right): \delta 3.71\left(\mathrm{~s}, 3 \mathrm{H}, \mathrm{CH}_{3} \mathrm{O}\right), 6.31(\mathrm{~s}, 1 \mathrm{H}, \mathrm{CH}), 6.80-7.93$ (m, 12H, ArH), 8.16-8.78 (m, 2H, OH).

\section{Conclusion}

In conclusion, we have developed a green, practical, and facile approach for the preparation of biscoumarin derivatives through the three-component reaction of 4-hydroxycoumarin and aromatic aldehydes using a catalytic amount of $\mathrm{CoCl}_{2} \cdot 6 \mathrm{H}_{2} \mathrm{O}$ as an efficient and inexpensive catalyst. The distinguished advantages of this procedure are (i) simple experimental procedure, (ii) mild reaction conditions, (iii) high to excellent yields of products, (iv) short reaction times, (v) and utilization of an inexpensive and readily available catalyst.

\section{Conflict of Interests}

The author declares that there is no conflict of interests regarding the publication of this paper.

\section{Acknowledgment}

The author gratefully acknowledges the financial support from the Research Council of Islamic Azad University, Shiraz Branch.

\section{References}

[1] I. Kostova, I. Manolov, and G. Momekov, "Cytotoxic activity of new neodymium (III) complexes of bis-coumarins," European Journal of Medicinal Chemistry, vol. 39, no. 9, pp. 765-775, 2004.

[2] I. Manolov, C. Maichle-Moessmer, and N. Danchev, "Synthesis, structure, toxicological and pharmacological investigations of 4-hydroxycoumarin derivatives," European Journal of Medicinal Chemistry, vol. 41, no. 7, pp. 882-890, 2006.

[3] N. Hamdi, M. C. Puerta, and P. Valerga, "Synthesis, structure, antimicrobial and antioxidant investigations of dicoumarol and related compounds," European Journal of Medicinal Chemistry, vol. 43, no. 11, pp. 2541-2548, 2008.

[4] C. C. Chiang, J. F. Mouscadet, H. J. Tsai, C. T. Liu, and L. Y. Hsu, "Synthesis and HIV-1 integrase inhibition of novel bis- or tetracoumarin analogues," Chemical and Pharmaceutical Bulletin, vol. 55, no. 12, pp. 1740-1743, 2007.

[5] D. Završnik, S. Muratović, S. Špirtović, D. Softić, and M. MedićŠarić, "The synthesis and antimicrobial activity of some 4hydroxycoumarin derivatives," Bosnian Journal of Basic Medical Sciences, vol. 8, no. 3, pp. 277-281, 2008.

[6] K. M. Khan, S. Iqbal, M. A. Lodhi, G. M. Maharvi, M. I. Choudhary, and S. Perveen, "Biscoumarin: new class of urease inhibitors; economical synthesis and activity," Bioorganic and Medicinal Chemistry, vol. 12, no. 8, pp. 1963-1968, 2004.

[7] M. Kidwai, V. Bansal, P. Mothsra et al., "Molecular iodine: a versatile catalyst for the synthesis of bis(4-hydroxycoumarin) methanes in water," Journal of Molecular Catalysis A: Chemical, vol. 268, no. 1-2, pp. 76-81, 2007.

[8] H. Mehrabi and H. Abusaidi, "Synthesis of biscoumarin and 3,4dihydropyrano[c]chromene derivatives catalysed by sodium dodecyl sulfate (SDS) in neat water," Journal of the Iranian Chemical Society, vol. 7, no. 4, pp. 890-894, 2010.

[9] J. M. Khurana and S. Kumar, "Tetrabutylammonium bromide (TBAB): a neutral and efficient catalyst for the synthesis of biscoumarin and 3,4-dihydropyrano[c]chromene derivatives in water and solvent-free conditions," Tetrahedron Letters, vol. 50, no. 28 , pp. 4125-4127, 2009.

[10] N. Tavakoli-Hoseini, M. M. Heravi, F. F. Bamoharram, A. Davoodnia, and M. Ghassemzadeh, "An unexpected tetracyclic product isolated during the synthesis of biscoumarins catalyzed by $\left[\mathrm{MIM}\left(\mathrm{CH}_{2}\right)_{4} \mathrm{SO}_{3} \mathrm{H}\right]\left[\mathrm{HSO}_{4}\right]$ : characterization and $\mathrm{X}$ ray crystal structure of 7-(2-hydroxy-4-oxo-4H-chromen-3-yl)$6 \mathrm{H}, 7 \mathrm{H}$-chromeno[4,3-b]chromen-6-one," Journal of Molecular Liquids, vol. 163, no. 3, pp. 122-127, 2011.

[11] A. Davoodnia, "A highly efficient and fast method for the synthesis of biscoumarins using tetrabutylammonium hexatungstate $[\mathrm{TBA}]_{2}\left[\mathrm{~W}_{6} \mathrm{O}_{19}\right]$ as green and reusable heterogeneous catalyst," Bulletin of the Korean Chemical Society, vol. 32, no. 12, pp. 4286-4290, 2011.

[12] B. Karmakar, A. Nayak, and J. Banerji, "Sulfated titania catalyzed water mediated efficient synthesis of dicoumarols-a green approach," Tetrahedron Letters, vol. 53, no. 33, pp. 43434346, 2012.

[13] K. Tabatabaeian, H. Heidari, A. Khorshidi, M. Mamaghani, and N. O. Mahmoodi, "Synthesis of biscoumarin derivatives by the reaction of aldehydes and 4-hydroxycoumarin using ruthenium(III) chloride hydrate as a versatile homogeneous catalyst," Journal of the Serbian Chemical Society, vol. 77, no. 4, pp. 407-413, 2012.

[14] B. Pawar, V. Shinde, and A. Chaskar, "n-Dodecylbenzene sulfonic acid (DBSA) as a novel Brønsted acid catalyst for the synthesis of bis(indolyl)methanes and bis(4-hydroxycoumarin3-yl)methanes in water," Green and Sustainable Chemistry, vol. 3, no. 2, pp. 56-60, 2013.

[15] R. Karimian, F. Piri, A. A. Safari, and S. J. Davarpanah, "Onepot and chemoselective synthesis of bis(4-hydroxycoumarin) derivatives catalyzed by nano silica chloride," Journal of Nanostructure in Chemistry, vol. 3, pp. 52-57, 2013.

[16] S. Velusamy, J. S. K. Kumar, and T. Punniyamurthy, "Cobalt(II) catalyzed tosylation of alcohols with p-toluenesulfonic acid," Tetrahedron Letters, vol. 45, no. 1, pp. 203-205, 2004.

[17] S. Velusamy, S. Borpuzari, and T. Punniyamurthy, "Cobalt(II)catalyzed direct acetylation of alcohols with acetic acid," Tetrahedron, vol. 61, no. 8, pp. 2011-2015, 2005.

[18] A. T. Khan, T. Parvin, and L. H. Choudhury, "A simple and convenient one-pot synthesis of benzimidazole derivatives using cobalt(II) chloride hexahydrate as catalyst," Synthetic Communications, vol. 39, no. 13, pp. 2339-2346, 2009.

[19] V. Padalkar, K. Phatangare, S. Takale, R. Pisal, and A. Chaskar, "Silica supported sodium hydrogen sulfate and Indion 190 resin: an efficient and heterogeneous catalysts for facile synthesis of bis-(4-hydroxycoumarin-3-yl) methanes," Journal of Saudi Chemical Society, 2012. 
[20] K. Niknam and A. Jamali, "Silica-bonded N-propylpiperazine sodium $n$-propionate as recyclable basic catalyst for synthesis of 3,4-dihydropyrano $[c]$ chromene derivatives and biscoumarins," Chinese Journal of Catalysis, vol. 33, no. 11, pp. 1840-1849, 2012.

[21] P. Singh, P. Kumar, A. Katyal et al., "Phosphotungstic acid: an efficient catalyst for the aqueous phase synthesis of bis(4-hydroxycoumarin-3-yl)methanes," Catalysis Letters, vol. 134, no. 3-4, pp. 303-308, 2010.

[22] K. P. Boroujeni and P. Ghasemi, "Synthesis and application of a novel strong and stable supported ionic liquid catalyst with both Lewis and Brønsted acid sites," Catalysis Communications, vol. 37, pp. 50-54, 2013. 

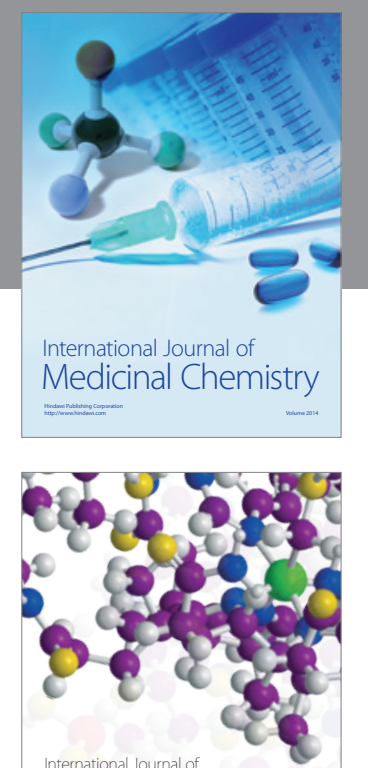

\section{Carbohydrate} Chemistry

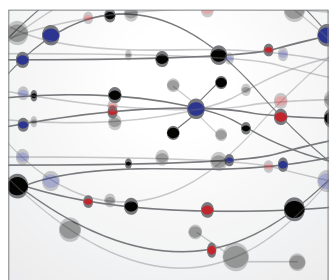

The Scientific World Journal
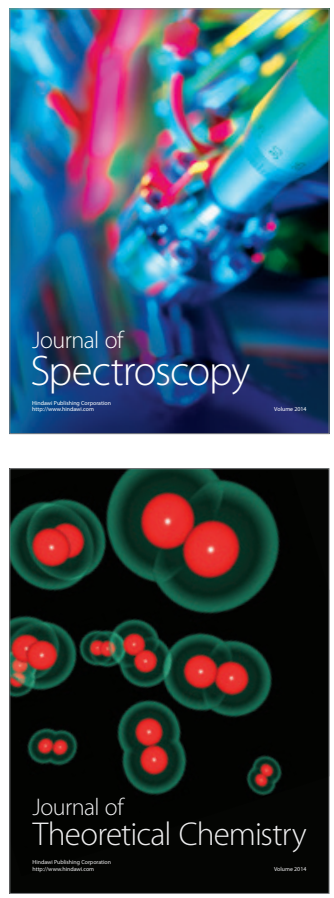
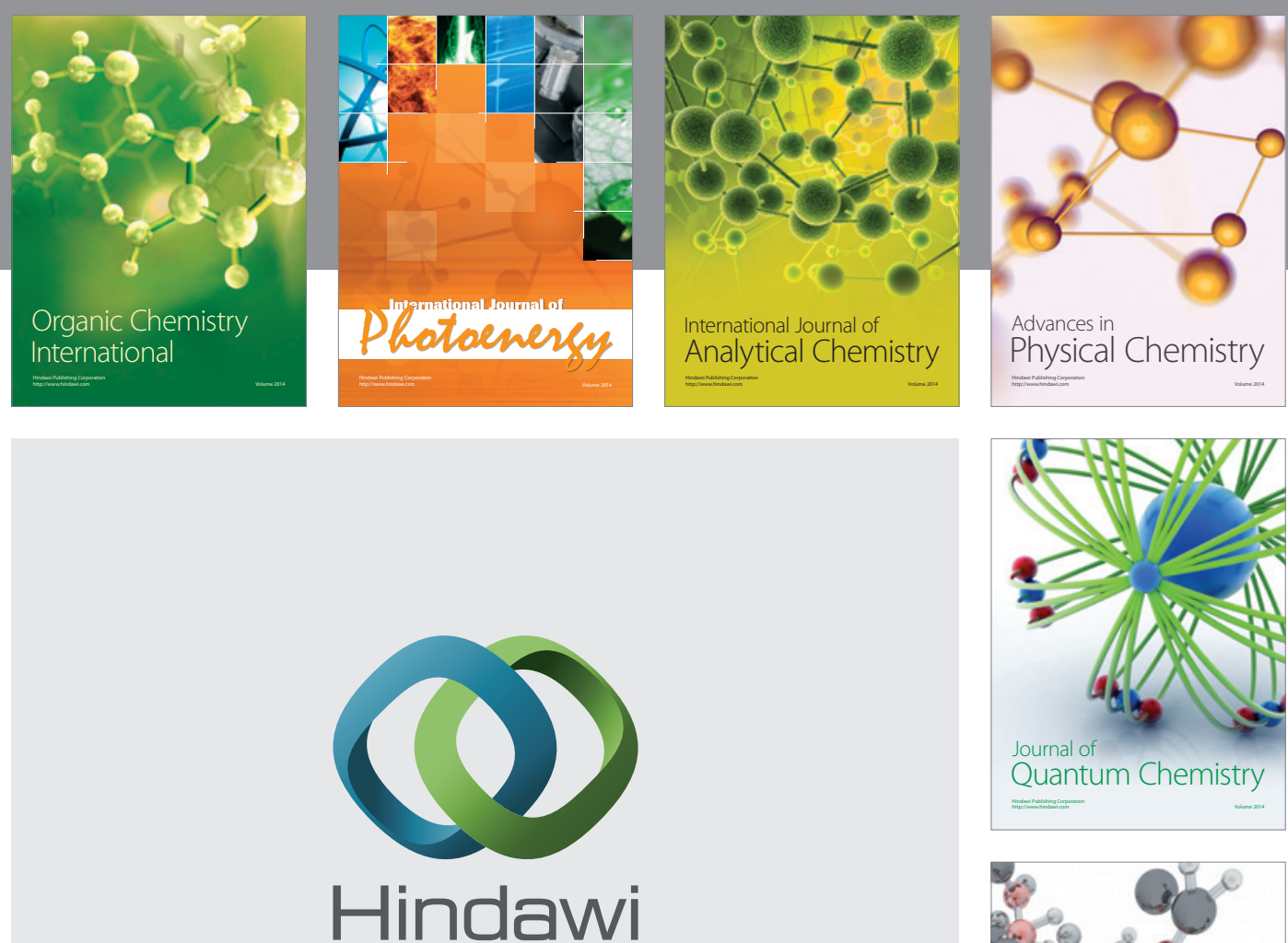

Submit your manuscripts at

http://www.hindawi.com

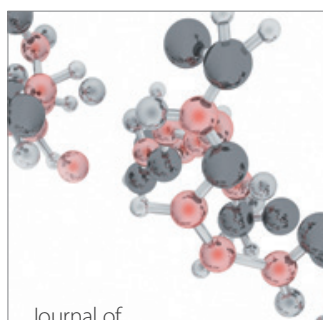

Analytical Methods

in Chemistry

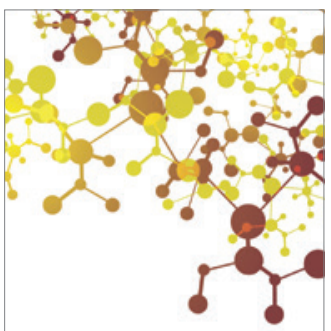

Journal of

Applied Chemistry

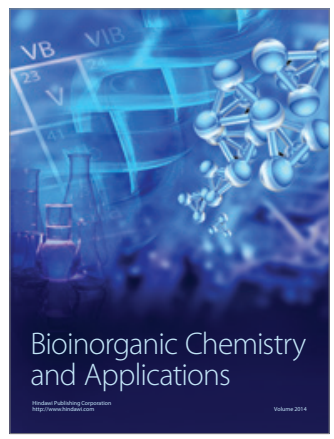

Inorganic Chemistry
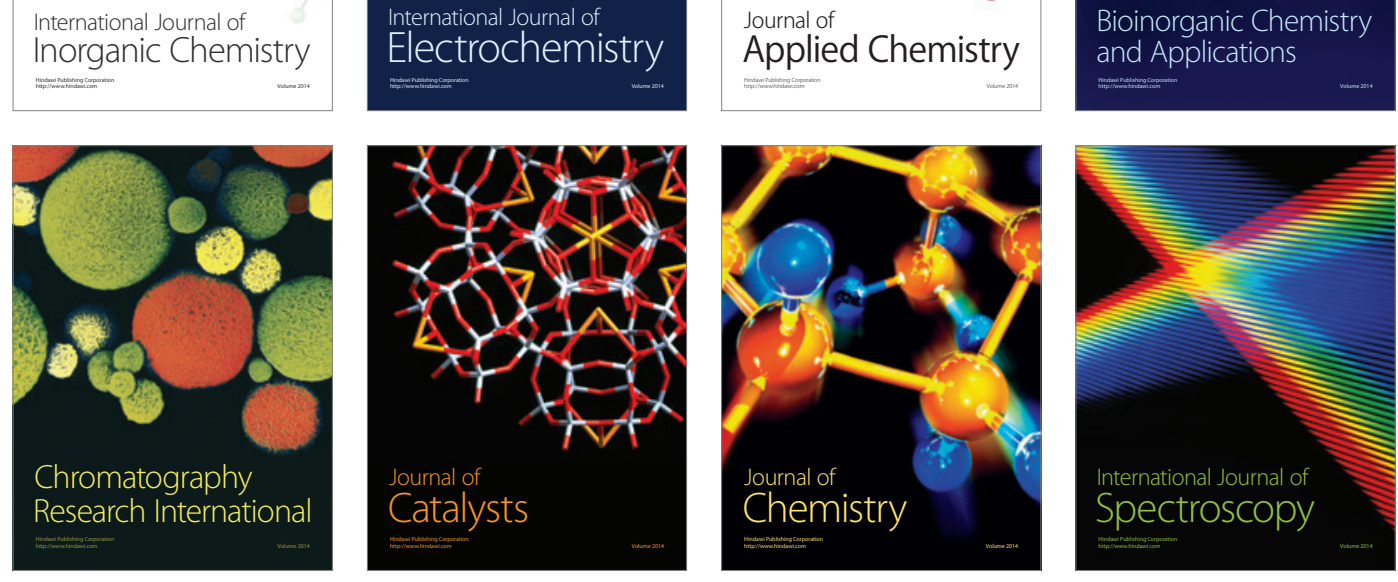